\title{
Problem-based learning in Gross Anatomy: Assessment Outcomes and Student Perceptions
}

\author{
Chunhua Chen \\ Department of Anatomy and Embryology, School of Basic Medical Sciences, Peking \\ University Health Science Center, 100191, Beijing, China \\ E-mail: cch@bjmu.edu.cn
}

Weiguang Zhang (Corresponding author)

Department of Anatomy and Embryology, School of Basic Medical Sciences, Peking

University Health Science Center, 100191, Beijing, China

Tel: 86-10-82801466_E-mail: zhangwg@bjmu.edu.cn

\section{Lihua Qin}

Department of Anatomy and Embryology, School of Basic Medical Sciences, Peking University Health Science Center, 100191, Beijing, China

E-mail: qinlihua88@bjmu.edu.cn

Haimeng Cui

Undergraduate-graduate clinical students (2009-2017) in Peking University Health Science Center, 100191, Beijing, China

E-mail: mengsky9@yeah.net

\section{Dandan Linghu}

Undergraduate-graduate clinical students (2010-2018) in Peking University Health Science Center, 100191, Beijing, China

E-mail: lhdd0359@163.com

\section{Youfei Guan}

Department of Physiology, School of Basic Medical Sciences, Health Science Center 
100191, Beijing, China

E-mail: youfeiguan@bjmu.edu.cn

\author{
Xian Wang \\ Department of Physiology, School of Basic Medical Sciences, Health Science Center \\ 100191, Beijing, China \\ E-mail: xwang@bjmu.edu.cn
}

Changman Zhou (Corresponding author)

Department of Anatomy and Embryology, School of Basic Medical Sciences, Peking University Health Science Center, 100191, Beijing, China

Tel: 86-010-82801164Ｅ-mail: changmanzhou@hotmail.com

Received: November 10, 2012 Accepted: November 23, 2012

doi:10.5296/jbls.v4i1.2639ＵＵＵ： http://dx.doi.org/10.5296/jbls.v4i1.2639

\begin{abstract}
This study aimed to study whether the problem-based learning (PBL) as an educational strategy can be of great help in improving the quality of gross anatomy and the attitude of students towards the learning method in China. It was performed in Basic Science of Peking University Health Science Center. The study sample included 200 students and they were assigned to 20 groups. Data collection was done by a questionnaire survey and interview to examine the students' learning attitudes and perceptions toward this platform as a possible learning tool. Data obtained were compared and the main themes were determined. At the end of data analyses, we gave feedback and evaluation. We found out the satisfaction of students with this learning method and the students' interest and ability improvement after this teaching method. Also, we showed the problems and largest obstacle that the students face in this learning mode and their expectant evaluation method. The study clearly pointed out that the PBL benefits a lot for the students in the study of gross anatomy despite of the existing problems. In the future, we should implement PBL combined with the characteristics of traditional anatomy teaching in China.
\end{abstract}

Key words: Problem based learning, Evaluation, Gross anatomy, Medical school. 


\section{Introduction}

Problem-based learning (PBL) was first employed in the 1960s in the Medical Education Department at McMaster University (Distlehorst et al., 2005). It is striking the traditional teaching patterns in China now. With the rapid progress of current curriculum reformation, the pattern of PBL was firstly introduced in the teaching of the basic science in Peking University. Although PBL have been elementary carried out in our previous anatomic courses (Wang et al., 2010), the present paper is the first observation of the PBL session of a case study of osteology in gross anatomy.

PBL is an educational approach that challenges students to 'learn to learn' and work co-operatively in groups to seek solutions (Haghparast et al., 2007). In this process, small groups of students are presented with contextual situations and asked to define the problem, decide what skills and resources are necessary to investigate the problem and then pose possible solutions. Students acquire knowledge skills and understanding through a staged sequence of problems presented in sequence (Leung et al., 2003). They arrive at decisions based on prior knowledge and reasoning. It is reported that PBL students generate explanations that are more accurate, coherent and comprehensive than non PBL students. And the effect is stronger for the full-time PBL students (Blake et al., 2000). At the same time, tutors play the most important role in the success of students exposed to PBL (Bowman \& Hughes, 2005).

Many reports claimed that PBL not only helps students in the acquisition of content knowledge but also promotes their learning in dealing with complex problems, enriches their learning of basic science information, leads them to self-directed life-long learning, improves the effectiveness of their communication, cooperative study and self-evaluation skills, and allows them to adapt to changes (Albanese \&Mitchell, 1993; Caplow et al., 1997; Schmidt et al., 2006; Schmidt et al., 2011)

However, some studies were not in favour of PBL (Bowman et al., 2005). A few might feel that PBL is a threat to basic science (particularly anatomy) education since the fundamentals of the disciplines may be neglected and there exists many problems. PBL teaching in anatomy courses of medical school is a highly controversial topic. The teachers doubt how to be a good tutor without lecture, and the students are unease how to capture the concept of each anatomy course without teachers' lecture. There have been few evaluations on the PBL teaching in anatomy courses in China. In our research, students studied osteology through discussion of a case about the osteoporosis, then they gave feedback in the form of questionnaire. The present paper aimed to evaluate what the students expect in this learning sessions, and how tutors' behavior affects students' experience.

\section{Experimental Procedures}

\subsection{Research Ethics}

All participants were informed of the purpose and design of the study. Each student was assured the data obtained and their identities would be confidential and anonymous. 


\subsection{Evaluation Design}

This evaluation was performed in Peking University Health Science Center.

The case is mainly about the osteoporosis: one old woman found that she was shorter than before by about $7 \mathrm{~cm}$ in 10 years with low serum calcium, high parathyroid hormone and had fracture of femur neck before. The students met to discuss about the case and the corresponding anatomy knowledge.

PBL has been used in the basic medical college in Peking University since 2009. Each small group with 10-11students works with a PBL tutor. Groups usually meet twice a week for around 2-3 hours and one case lasts for two weeks on average. Students are presented with an unfamiliar situation or problem, identify the main issues and formulate questions to work on at the first meeting. The group members are reconvened following a period of individual study (2-3 days). They discuss what they have learnt and try to answer the original problem. Tutors give feedback to each student at the end of each PBL session in each module. Individual feedback is given when students are alone. Students' performances are evaluated through examinations in the middle of each semester and a score for each student is completed by tutors at each PBL session.

The number of students involved in this study was about 200. The PBL program split them into 20 different groups and they all agreed to participate in the study. The number of questionnaire got back from the students was 157. The interviews were undertaken at the end of the PBL learning. The average age of the students was 20.22 yrs.

As there have been not much experiences of PBL in anatomy courses in China, in order to obtain detailed information, questionnaire and group interviews were used in the present evaluation to obtain the students' opinions and feelings to the case of osteoporosis.

\section{Results}

\subsection{Survey of Students' Learning Situation}

\subsubsection{Satisfaction of Students with PBL in Anatomy Courses}

Approximately $80 \%$ of the students felt satisfied with their achievement in this case. Meanwhile just 9\% were not satisfied with it. The others (11\%) were indifferent to it. The questionnaire result showed that $45.22 \%$ of the students were more accustomed to traditional anatomy teaching method and relied on the lectures and demonstration from tutors (teachers). The reason of un-satisfaction may be from their limited theoretical knowledge. $30.57 \%$ of the students doubted the efficiency of PBL at the beginning of the new teaching mode. However, after some cases, $78.1 \%$ of them promoted their interest and enthusiasm.

\subsubsection{Improvement of Students’ Ability}

As shown in Table 1, through the study of this case, $95.4 \%$ of the students believed that this teaching mode enhanced their skills to ask questions and solve problems; $95.5 \%$ of them considered that PBL learning improved their self-learning ability, expanded their knowledge; $87.1 \%$ of them thought they had improved the ability to cooperate with each other. 
Table 1 Survey Results

\begin{tabular}{l|l|l|l|l}
\multicolumn{1}{c|}{ The influence of PBL } & strong & Median & weak & No \\
\cline { 2 - 5 } & 3 & 2 & 1 & 0 \\
\hline S1:Improve the students' interest and learning enthusiasm & $79(50.31 \%)$ & $70(44.58 \%)$ & $6(3.82 \%)$ & $2(1.27 \%)$ \\
\hline $\begin{array}{l}\text { S2: Enhance the ability of using theory and strengthen the links } \\
\text { between the courses }\end{array}$ & $104(66.24 \%)$ & $51(32.48 \%)$ & $2(1.27 \%)$ & 0 \\
\hline S3: Enhance self-learning ability & & & \\
\hline $\begin{array}{l}\text { S4: Enhance the communication between the students and } \\
\text { between the teachers and students }\end{array}$ & $74(47.13 \%)$ & $61(38.85 \%)$ & $19(12.10 \%)$ & $3(1.91 \%)$ \\
\hline S5:Improve the ability of organization and coordination & $81(51.59 \%)$ & $63(40.13 \%)$ & $11(7.01 \%)$ & $2(1.27 \%)$ \\
\hline S6: Influence the self-confidence & $56(35.67 \%)$ & $82(52.23 \%)$ & $16(10.19 \%)$ & $3(1.91 \%)$ \\
\hline S7: Find and set learning goals & $51(32.48 \%)$ & $83(52.87 \%)$ & $18(11.46 \%)$ & $5(3.18 \%)$ \\
\hline S8: Problem analysis and problem-solv ing skills & $80(50.96 \%)$ & $70(44.5 \% \%)$ & $6(3.82 \%)$ & $1(0.64 \%)$ \\
\hline S9: Literature search and arrangement ability & $95(60.51 \%)$ & $56(35.61 \%)$ & $6(3.82 \%)$ & 0 \\
\hline S10: Collaboration between the students on solving problems & $59(37.58 \%)$ & $78(49.68 \%)$ & $16(10.19 \%)$ & $4(2.55 \%)$ \\
\hline
\end{tabular}

\subsection{Survey of Tutors' Teaching Situation}

\subsubsection{Tutors' Teaching Attitude}

Data analysis of the question "when encounter difficulties, you ask for the help from your tutors, what is their reaction?” showed that there was $75.15 \%$ of students held a positive attitude to tutors' teaching attitude (Figure 1).

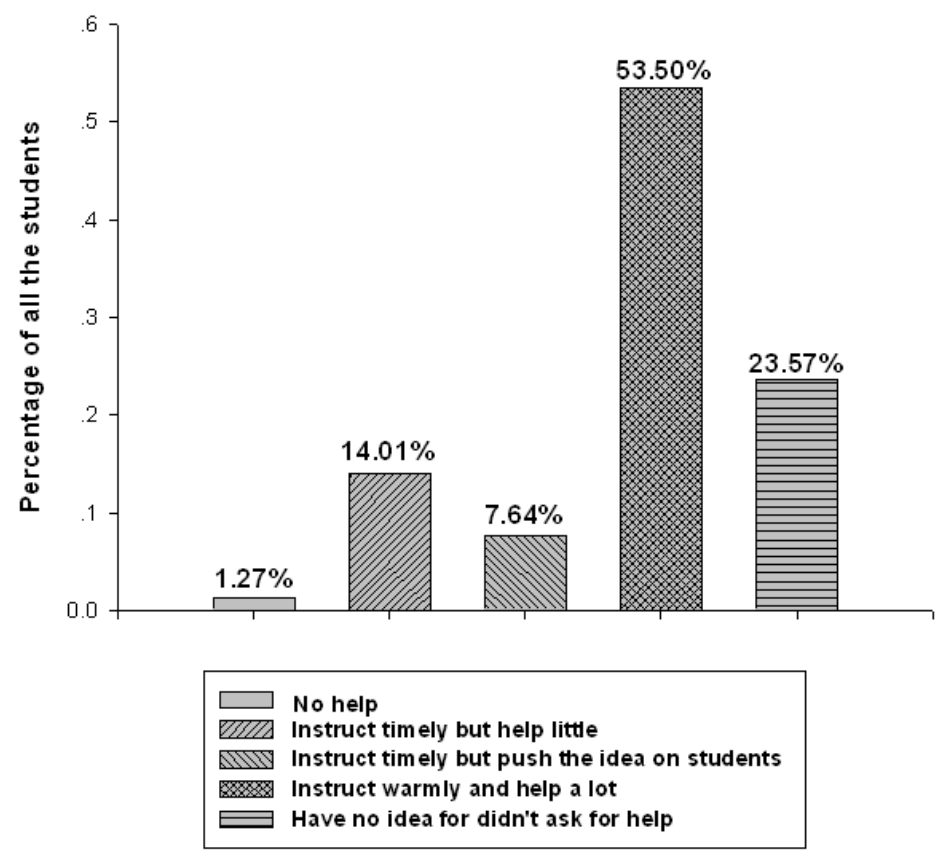

Figure 1. The attitude of tutors in the course of PBL when asked for help. Most of the students thought that the tutors instructed warmly and helped a lot. However, there were still $23.57 \%$ of the students who didn't ask for help at all.

\subsubsection{Tutors' Teaching Method}

Data analysis of the question "when tutors interspersed with some guidance and explanation in the course of case study, what is your feelings?” showed that there was $66.88 \%$ of students 


\section{Macrothink}

believed that tutors' explanation was very necessary, concise and proper. 14.01\% of students reflected that the explanation was not sufficient and detailed (Figure 2). The results told us that tutors played guiding roles in students' learning activities. Tutors must grasp the scale of the guide although it's difficult because of the difference in students' understanding and original knowledge. We hypothesized that the un-satisfaction came from different knowledge levels.

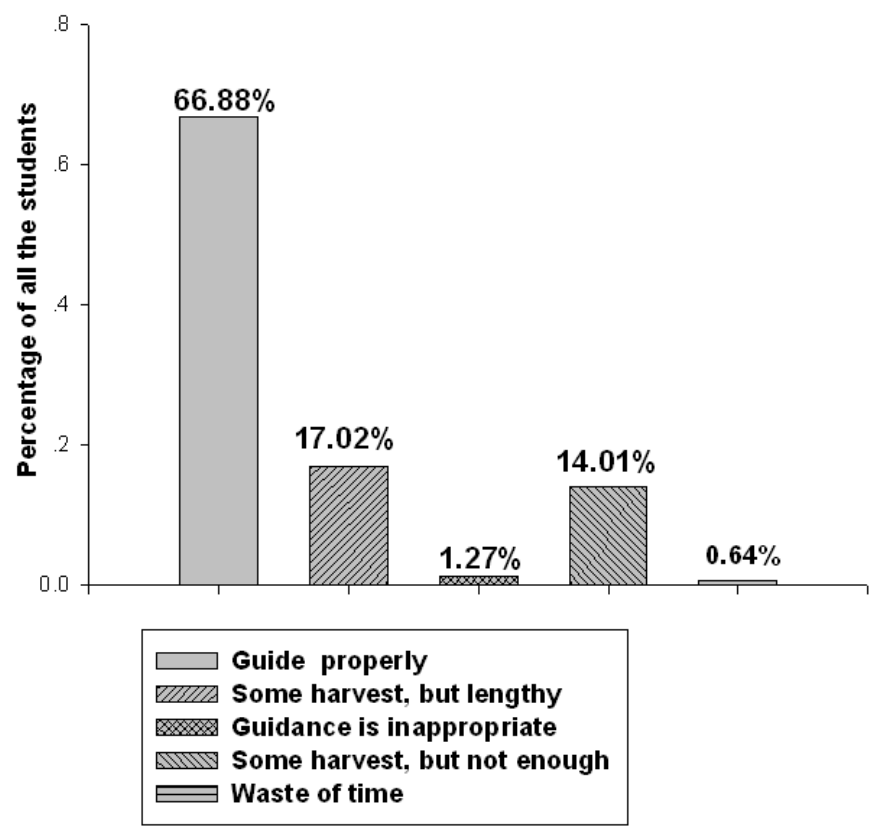

Figure 2. The feelings of students on the guidance and explanation of the tutors in this course of PBL teaching. Most of them thought it was very necessary and the guidance was concise and proper. However, $17.2 \%$ of the students thought they had some harvest but the explanation seemed too long.

\subsection{Evaluation of the learning effect}

\subsubsection{Group Discussion}

In the case study, most students actively participated in group discussion, but there were still a few students always being silent. Through individual interviews, some students reflected that they didn't want to speak, as long as they have understood the knowledge. Another part of silent students did not accept the teaching mode and were accustomed to traditional teaching mode.

\subsubsection{Expectant Evaluation}

The purpose of evaluation is to evaluate the learning efficiency from the application of PBL, and more importantly, to stimulate the enthusiasm of the students. But in our observation, the evaluation from the tutors tended to cause students' resentment. The questionnaire showed that only $14.01 \%$ of the students felt satisfied with the evaluation as shown in Figure3. 56.05\% of students believed that this evaluation brought a heavy burden. In addition, the evaluation from the tutors in the case study is quite subjective. So the tutors should try to make a relatively objective and impartial evaluation. Otherwise, it is difficult for students to convince. 


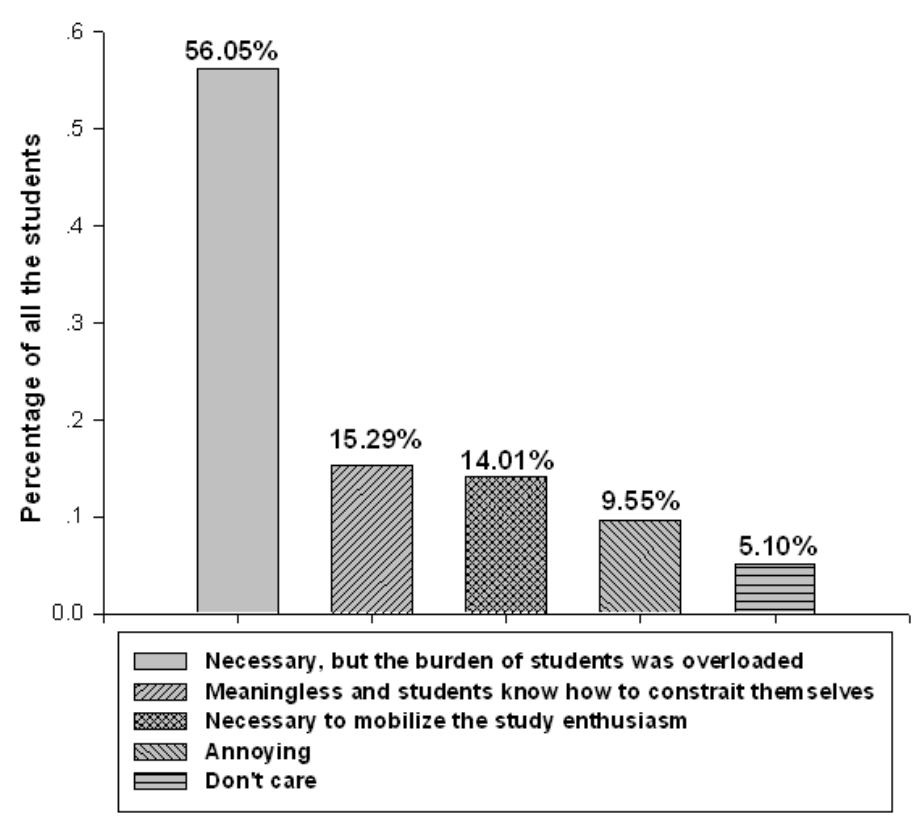

Figure 3. The feeling of students towards the examination used in the mid-term of PBL process. Majority of students (56.05\%) thought that the examination was necessary, but the burden of students was overloaded.

The "what is the evaluation method the students most expect" survey as shown in Figure 4 pointed out that the majority of students expect the tutors to give comments (37.58\%) or face-to-face communication (29.94\%). We interviewed some students and they believed that the fundamental goal of evaluation was to encourage students to work co-operatively and solve problems. However, our evaluation not only failed to achieve this goal, but transferred the attention of students to the final score.

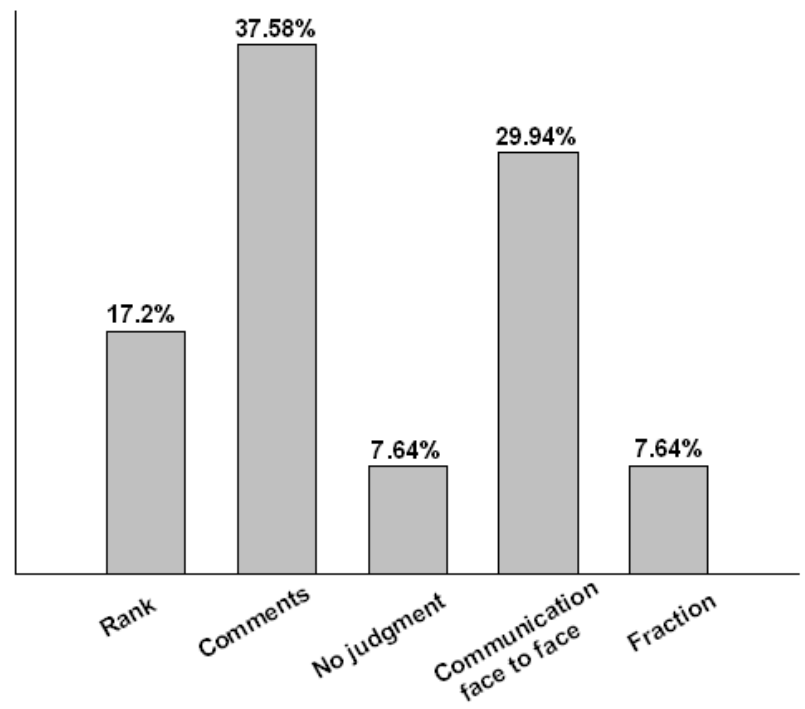

Figure 4. The evaluation way from the tutors that the students most expected. The figure pointed out that the majority of students expected comments from tutors (37.58\%) or face-to-face communication (29.94\%). 


\section{Discussion}

The students as well as the tutors had encountered great challenges in this case study when transitioning from traditional anatomy study to PBL. Previous study showed that, self-directed learning in PBL could range from pre-organized teaching, student-initiated but instructor-guided learning, to completely self-taught learning (Miflin, 2004a; Miflin, 2004b). Our interview and questionnaire results showed the PBL of gross anatomy in medical school could improve the ability of students but there were still many problems which were summarized as follows:

\subsection{The Problems Existing in the Students}

\subsubsection{The Conflict Emotion in Initial Study}

In present observation, some of the students felt difficult to accept the new teaching mode, especially in initial study. They performed in the following aspects: prepare careless before class to cope with the inspection; silent in the group discussion; discard the PBL immediately after class. For these problems above, tutors should make students truly understand the PBL theory. As Maudsley stated (Maudsley, 1999), the effectiveness of tutors is essential to the success of PBL. In initial study, tutors could use PBL and traditional teaching method together as an interim.

\subsubsection{The Burden on Students is Over-weight}

The PBL mode in anatomy in Peking University is new and the students need to spend more time to accustom to it. Schmidt et al. (Norman et al., 1992) reported that students need at least 6 months to adapt to this new instructional method. In our observation, the complaints were often heard after class. Students felt they were forced to search for information and write analysis report. In the future study, students should try their best to understand the advantage of PBL and change the original feeling. Tutors should strengthen their guidance in the early stage, and gradually reduce guidance.

\subsection{The Obstacles in Group Discussion}

\subsubsection{Capacity Difference in Team Members}

Cooperative learning is one of the most important features of PBL. Mutual assistance can effectively improve individual learning ability. The group was randomly formed of clinical and basic science students and each group was in similar condition. But the character and knowledge reservation of each group member were varied. The students with high enthusiasm should bring the introverted students along and leave more opportunities to them. Only in this way can we mobilize the participation of all the students. At the same time, the tutors must use more skills to motivate the students with different ability and make all of them to participate in discussion.

\subsubsection{Group Discussion Failure}

Group discussion failure mainly displays in the following aspects: Firstly, group discussion was entangled at some aspects, and ignored other aspects; Secondly, "lazy" members existed in 
small groups; Thirdly, the weak members in group were ignored by the strong ones; Fourthly, "centralized" members existed in the groups who blocked the communication of other members; Fifthly, small groups were lack of active participation. For the above problems, the tutor should create happy atmosphere for the students to express their own opinions. If the students thought they would take risks while they talk something following their heart, or might be laughed by other classmates, they would not be willing to participate in the discussion.

\subsection{The Problems Existing in Tutors}

\subsubsection{Tutor s’ Guidance}

The traditional gross anatomy were taught by teachers directly, but in PBL process, the role of the tutor is to guide and facilitate learning (Albanese et al.,1993). Proper guiding from tutors may promote the learning effect. In our observation, some students thought the tutors' guidance was too lengthy. Some thought it was not detailed enough to understand. There are two reasons for this problem: firstly, with the shift of tutors' role, the policy of "let go" made the students felt losing the backbone of study. Secondly, because of the wide differences of students, the same explanation from the tutors was difficult to meet the needs of them all. Therefore, tutors should take the individual students into account and guide individually if necessary.

\subsubsection{Tutors’ Evaluation}

Jost et al. found that the students' anxiety in the PBL process mainly resulted from their uncertainty about their roles and responsibilities in the course and how they would be evaluated (Jost et al., 1997). In our teaching process, evaluation and learning blended into one harmonious whole. Tutors used the assessment of giving comments combined with mid-term scores from examination. A lot of students expressed their dissatisfaction for this evaluation. They thought it was not necessary to use the mid-term examination that not only dampened the enthusiasm, but also gave them more burdens. For this problem, we would substitute quantitative scores to subjective suggestions and communication. A piece of paper or a score can't serve as a standard in the complex PBL process.

\section{Summary}

Therefore, to improve the tutors' teaching skill and mobilize students' enthusiasm are very important to the education reformation. In the future application, we should implement the PBL mode based on the characteristics of gross anatomy teaching in China. This teaching mode will definitely become the emphasis of the reformation of medical education and development trend in our country.

\section{Acknowledgement}

The research is financed by the Chinese National Basic Science Education Grant (J1103605/J0108) 


\section{References}

Albanese, M. A., \& Mitchell, S. (1993). Problem-based learning: a review of literature on its outcomes and implementation issues. Acad. Med., 68(1), 52-81. http://dx.doi.org/10.1097/00001888-199301000-00012

Blake, R. L., Hosokawa, M. C., \& Riley, S. L. (2000). Student performances on Step 1 and Step 2 of the United States Medical Licensing Examination following implementation of a problem-based learning curriculum. Acad. Med., 75(1), 66-70. http://dx.doi.org/10.1097/00001888-200001000-00017

Bowman, D., \& Hughes, P. (2005). Emotional responses of tutors and students in problem-based learning: lessons for staff development. Med. Educ., 39(2), 145-153. http://dx.doi.org/10.1111/j.1365-2929.2004.02064.x

Caplow, J. A., Donaldson, J. F., Kardash, C., \& Hosokawa M. (1997). Learning in a problem-based medical curriculum: students' conceptions. Med. Educ., 31(6), 440-447. http://dx.doi.org/10.1046/j.1365-2923.1997.00700.x

Distlehorst, L. H., Dawson, E., Robbs, R. S., \& Barrows, H. S. (2005). Problem-based learning outcomes: the glass half-full. Med. Educ., 80(3), 294-299. http://dx.doi.org/10.1097/00001888-200503000-00020

Haghparast, N., Sedghizadeh, P. P., Shuler, C. F., Ferati, D., \& Christersson, C. (2007). Evaluation of student and faculty perceptions of the PBL curriculum at two dental schools from a student perspective: a cross-sectional survey. Eur. J. Dent. Educ., 11(1), 14-22. http://dx.doi.org/10.1111/j.1600-0579.2007.00423.x

Jost, K. L., Harvard, B. C., \& Smith, A. J. (1997). A study of problem-based learning in a graduate education classroom. In Proceedings of Selected Research and Development Presentations at the 1997 National Convention of the Association for Educational Communications and Technology, February 14-18, Albuquerque, NM (ERIC Document Reproduction Service No. ED 409-840).

Leung, K. K., Lue, B. H., \& Lee, M. B. (2003). Development of a teaching style inventory for tutor evaluation in problem-based learning. Med. Educ., 37(5), 410-416. http://dx.doi.org/10.1046/j.1365-2923.2003.01493.x

Maudsley, G. (1999). Roles and responsibilities of the problem based learning tutor in the undergraduate medical curriculum. BMJ, 318(7184), 657-661. http://dx.doi.org/10.1136/bmj.318.7184.657

Miflin, B. (2004). Problem-based learning: the confusion continues. Med. Educ., 38(9), 923-925. http://dx.doi.org/10.1111/j.1365-2929.2004.01920.x

Miflin, B. (2004). Small groups and problem-based learning: are we singing from the same hymn sheet? Med. Teach., 26(5), 444-450. http://dx.doi.org/10.1080/01421590410001696425

Norman, G. R., \& Schmidt, H. G. (1992). The psychological basis of problem-based learning: 


\section{Macrothink}

Journal of Biology and Life Science

ISSN 2157-6076 2013, Vol. 4, No. 1

a review of the evidence. Acad. Med., 67(9), 557-565. http://dx.doi.org/10.1097/00001888-199209000-00002

Schmidt, H. G., Rotgans, J. I., \& Yew, E. H. (2011). The process of problem-based learning: $\begin{array}{lllll}\text { what works and why. } & \text { Med. Educ., 45(8), }\end{array}$ http://dx.doi.org/10.1111/j.1365-2923.2011.04035.x

Schmidt, H. G., Vermeulen, L., \& van der Molen, H. T. (2006). Longterm effects of problem-based learning: a comparison of competencies acquired by graduates of a problem-based and a conventional medical school. Med. Educ., 40(6), 562-567. http://dx.doi.org/10.1111/j.1365-2929.2006.02483.x

Wang, J., Zhang, W., Qin, L., Zhao, J., Zhang, S., Gu, J., \& Zhou, C. (2010). Problem-based learning in regional anatomy education at Peking University. Anat. Sci. Educ., 3(3), 121-126.

\section{Copyright Disclaimer}

Copyright reserved by the author(s).

This article is an open-access article distributed under the terms and conditions of the Creative Commons Attribution license (http://creativecommons.org/licenses/by/3.0/). 